\title{
¿Son útiles las nuevas tecnologías 2.0 como herramienta docente e informativa de la enfermedad renal?
}

\author{
Neus Franch Ciuraneta, Vanesa Sáez González, Jerónimo Ruiz Gallardo, Mª Antonia Bauça Capella, María \\ Guenoun Sanz
}

Hospital Universitario Son Espases. Baleares

\section{Introducción:}

Con la incorporación de las nuevas tecnologías en la información y comunicación, y ante la necesidad de formar a nuevos profesionales en el conocimiento de la enfermedad renal y realizar educación sanitaria al enfermo renal, se ha llevado a cabo en la unidad de diálisis de nuestro hospital la creación de un blog informativo sobre los protocolos y procedimientos usados en los cuidados más relevantes del paciente renal tanto en su tratamiento dialítico como en los aspectos de la vida cotidiana. La idea de crear este blog surgió cuando varios de los profesionales que atendemos al paciente renal crónico pensamos que sería interesante que los enfermos renales tuvieran un lugar al que poder consultar sus dudas e inquietudes sobre su enfermedad y que fuera información veraz y de contenido científico, pero que al mismo tiempo pudieran comprender toda la información. Los profesionales tanto de nueva incorporación como los contratados para sustituciones en periodo vacacional necesitan formarse tanto práctica como teóricamente. En nuestro hospital se les proporciona un periodo de aprendizaje de un mes junto a otro profesional, también se facilitan los procedimientos y protocolos de la unidad. Disponer de un lugar Web donde se recogen textos relacionados con esa actividad, es una manera actualizada de recibir información y tal vez más interesante para los profesionales y usuarios de cualquier parte del mundo.

\section{Objetivos:}

Principales: Comprobar la utilidad del blog en la formación de los profesionales e información a los usuarios sobre la enfermedad renal.
Secundarios: Crear un vínculo entre los profesionales y los pacientes renales, donde aclarar situaciones y problemas que pueden surgir derivados del estilo de vida y tratamiento de la enfermedad renal.

Dar apoyo emocional a los usuarios del blog.

\section{Material y método:}

Creación de un blog en internet el 10 de julio de 2012 que permite contabilizar el número de entradas para cada publicación así como las realizadas de distintos países. Utilización de cámara fotográfica digital. Metodología cualitativa que clasifica las opiniones volcadas en el blog en diferentes categorías temáticas: Resultados Tras el análisis de los datos estadísticos ofrecidos por el blog se constata la visita de 10 países, 7 de ellos latinoamericanos, 1 norteamericano, 1 asiático y España, con un total de 21680 en 8 meses. Las categorías encontradas son: Apoyo emocional profesionales, apoyo formativo a profesionales, apoyo emocional a pacientes y apoyo formativo a pacientes.

\section{Conclusión:}

Los profesionales se sienten apoyados en su labor diaria con las experiencias relatadas del día a día de la unidad. Se valora los "pequeños trucos" de las técnicas que desarrollamos para solventar los problemas. Los protocolos de la unidad han sido mejor valorados. Los pacientes han visto sus dudas solucionadas y agradecen el apoyo emocional que ofrece el blog con su mensaje positivo diario. La mayoría de los visitantes animan a seguir con el blog, 
nos felicitan por la iniciativa y siguen demandando soluciones a los problemas con su enfermedad.

\section{Referencias Bibliográficas}

1. AC Jiménez - ENE, Revista de Enfermería, 2012 ene-enfermeria.org.

2. Malbernat, Lucía Rosario (2010). «Tecnologías educativas e innovación en la Universidad.
3. Bruno Ortiz (2009). «En solo 40 años internet ha modificado nuestro mundo» (en español). Consultado el 29-11-2009.

4. Richard MacManus (21-02-2008). «Top Health 2.0 Web Apps» (en inglés). Read Write Web. Consultado el 29-11-2009.

5. Sandra Fernández González, ¿Qué son las nuevas tecnologías?. 